\title{
Association studies between the HSD11B2 gene (encoding human 11 $\beta$-hydroxysteroid dehydrogenase type 2), type 1 diabetes mellitus and diabetic nephropathy
}

\author{
Gareth G Lavery $^{1}$, Claire L McTernan ${ }^{1}$, Stephen C Bain ${ }^{2}$, Tahseen A Chowdhury ${ }^{3}$, Martin Hewison ${ }^{1}$ and \\ Paul M Stewart ${ }^{1}$ \\ ${ }^{1}$ Division of Medical Sciences, University of Birmingham, Queen Elizabeth Hospital, Edgbaston, Birmingham B15 2TH, UK, ${ }^{2}$ Birmingham Heartlands \\ Hospital, Bordesley Green East, Birmingham B9 5SS, UK and ${ }^{3}$ Jeffrey Kelson Diabetic Centre, Central Middlesex Hospital, London NW10 7 NS, UK \\ (Correspondence should be addressed to Paul M Stewart; Email: p.m.stewart@bham.ac.uk)
}

\begin{abstract}
Objective: Mutations in the HSD11B2 gene (encoding human 11 $\beta$-hydroxysteroid dehydrogenase type 2) explain the syndrome of apparent mineralocorticoid excess where cortisol acts as a mineralocorticoid. A microsatellite marker within the HSD11B2 gene associates with salt sensitivity and hypertension - phenotypes characterising diabetic nephropathy. Here, we evaluate the HSD11B2 gene as a susceptibility locus for diabetic nephropathy.

Design: 150 patients with type 1 diabetes and nephropathy (DN), 145 patients with type 1 diabetes with a long duration of non-nephropathy (LDNN) and 151 normal controls were studied.

Methods: We determined allele frequencies for the $(\mathrm{CA})_{\mathrm{n}}$ repeat marker within intron I of the HSD11B2 gene. Duration of type 1 diabetes, diabetic status and renal function were recorded.

Results: 11 alleles (138-158) for the marker were observed. Allele 152 was significantly increased in controls compared with $\mathrm{LDNN}\left(70.5 \%\right.$ vs $57.6 \%, P_{\mathrm{c}}<0.05$ where $P_{\mathrm{c}}$ is the $P$ value corrected for multiple comparisons) but no difference was observed between DN and LDNN subjects. Allele 154 was significantly increased in the LDNN compared with the DN subjects $\left(15.9 \%\right.$ vs $\left.7.0 \%, P_{\mathrm{c}}<0.01\right)$ but no difference was observed between DN and controls. A greater proportion of subjects carried at least 1 allele $<152$ in DN compared with control subjects $\left(47.3 \%\right.$ vs $\left.28.5 \%, P_{\mathrm{c}}<0.01\right)$, but no difference was observed in LDNN compared with control and DN subjects.

Conclusions: Weak associations are reported between the HSD11B2 gene, type 1 diabetes mellitus and nephropathy. The increased frequency of HSD11B2 short alleles in the diabetic groups may reflect

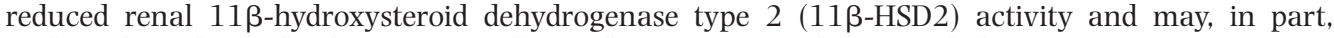
explain the enhanced salt sensitivity observed in patients with type 1 diabetes.
\end{abstract}

European Journal of Endocrinology 146 553-558

\section{Introduction}

11ß-Hydroxysteroid dehydrogenase type $2(11 \beta$-HSD2) plays a crucial role in converting hormonally active cortisol to inactive cortisone, thereby conferring specificity upon the mineralocorticoid receptor (MR) (1). Mutations in the gene encoding 11ß-HSD2 (HSD11B2) account for an inherited form of hypertension, the syndrome of 'apparent mineralocorticoid excess' (AME) where cortisol induces hypertension and hypokalaemia (2-4). A similar clinical picture occurs following the ingestion of liquorice and carbenoxolone, which are competitive inhibitors of $11 \beta-H S D 2$ (5). The principal site of $11 \beta-H S D 2$ expression is the kidney, and inhibition of the enzyme has also been documented in patients with non-diabetic renal disease and nephrotic syndrome (6), suggesting that impaired cortisol metabolism may contribute to sodium retention in these conditions. Conversely, loss of $11 \beta-\mathrm{HSD} 2$ may predispose to renal disease. Thus, patients with AME display abnormal renal histology with interstitial fibrosis (7) and recombinant mice lacking the gene encoding 11ß-HSD2 show hypertrophy and hyperplasia of the distal nephron (8). These observations highlight the potential importance of $11 \beta-H S D 2$ expression in renal physiology.

Diabetic nephropathy is the most common cause of end-stage renal failure in the Western world and one which contributes to the excess morbidity and mortality of patients with type 1 diabetes (9). Genetic factors are thought to contribute to the pathogenesis of nephropathy, as demonstrated by familial clustering of nephropathy (10). Earlier studies from our group have evaluated a series of candidate genes including the angiotensin converting enzyme, angiotensinogen (11) and the angiotensin II type 1 receptor (12). 
Although the underlying pathogenesis of nephropathy is unclear, an increase in exchangeable sodium accompanied by extracellular volume expansion has been documented and may contribute to the blood pressure rise associated with microalbuminuria (13, 14). Mechanisms responsible for this aberrant sodium retention are poorly understood, although increased renal tubular sodium resorption may play an intrinsic role. In particular, salt sensitivity in type 1 diabetic patients is associated with the development of nephropathy $(15,16)$. Recent data have revealed that salt sensitivity is associated with polymorphic markers in the human HSD11B2 gene $(17,18)$. In particular, shorter alleles for an informative microsatellite $(\mathrm{CA})_{\mathrm{n}}$ repeat marker within intron $\mathrm{I}$ of the HSD11B2 gene predict salt sensitivity and are associated with reduced $11 \beta$-HSD2 activity as inferred from urinary cortisol/cortisone metabolites (17). Finally, angiotensin converting enzyme (ACE) inhibitors are known to increase renal $11 \beta$-HSD2 activity (19, 20) and this, in part, may explain their protective effect against nephropathy.

On this basis we have formulated the hypothesis that reduced $11 \beta-H S D 2$ expression may play a role in the pathogenesis of diabetic nephropathy. This may result in salt sensitivity with predisposition to hypertension or may contribute to the development of nephropathy itself. Here we assess the frequency of a $(\mathrm{CA})_{n}$ dinucleotide microsatellite repeat located in the first intron of the HSD11B2 gene with the aim of determining whether polymorphisms at this microsatellite locus are associated with diabetic nephropathy in a cohort of type 1 diabetic patients.

\section{Materials and methods}

\section{Subjects}

The patients in this study have been described previously (11). Briefly, two white Caucasian type 1 diabetic cohorts and a non diabetic control group were analysed.

Group 1: type 1 diabetic patients with nephropathy (DN) classified by the presence of persistent proteinuria (in the absence of other causes), retinopathy and hypertension $(n=150)$. Group 2: type 1 diabetic patients with long duration non-nephropathy (LDNN), i.e. without evidence of nephropathy for at least fifteen years post diagnosis $(n=145)$. Group 3: non-diabetic adult control subjects recruited from the Blood Transfusion Service in order to determine allele frequencies in the background population. These subjects had no known first-degree relatives with type 1 diabetes $(n=151)$.

\section{Automated fluorescent genotyping and analysis of PCR product containing the HSD11B2 $(C A)_{n}$ repeat sequence}

Leukocyte DNA was collected from each subject. PCR primers $5^{\prime} \mathrm{CA} 5$ TCAGGTCAGAACTGGGAGGTC ${ }^{\prime}$ (sense) and CA3 5'TGGAGAGGGAGGCAAGCATAT3' (antisense), were used to amplify the HSD11B2 gene intron $\mathrm{I} \mathrm{CA}_{(\mathrm{n})}$ repeat microsatellite region. The reactions were performed with $40 \mathrm{ng}$ genomic DNA in a $25 \mu \mathrm{l}$ reaction volume containing $1 \mathrm{mmol} / \mathrm{l}$ magnesium chloride, $1 \times$ PCR buffer, $8 \mathrm{mmol} / \mathrm{l}$ of each dNTP and 1 unit Amplitaq Gold taq polymerase (Applied Biosystems, Foster City, CA, USA). The forward primer was end-labelled with a HEX fluorescent dye (Oswell, UK). The cycling conditions were as follows: an initial $95^{\circ} \mathrm{C} \times 10 \mathrm{~min}$ Taq activation step, followed by 30 cycles of $95^{\circ} \mathrm{C} \times 25 \mathrm{~s}, 55^{\circ} \mathrm{C} \times 25 \mathrm{~s}$ and $72^{\circ} \mathrm{C} \times 25 \mathrm{~s}$.

Each cohort was analysed using an ABI Prism 377 DNA sequencer (Applied Biosystems) for microsatellite repeat length variation. The PCR product for each subject was mixed with the internal size standard (Applied Biosystems) labelled with TAMRA red fluorescent dye. The mixture was then resolved by electrophoresis on a 5\% denaturing polyacrylamide gel. The internal size standard was used to create a calibration curve of peak arrival time which, in turn, was used to calculate

Table 1 Clinical characteristics of patients in the two type 1 diabetic cohorts being used for the genetic analysis. Data are means \pm S.D.

\begin{tabular}{lccc}
\hline & $\begin{array}{c}\text { Diabetic } \\
\text { nephropathy (DN) } \\
(n=150)\end{array}$ & $\begin{array}{c}\text { Long duration non } \\
\text { nephropathy (LDNN) } \\
(n=145)\end{array}$ & $\boldsymbol{P}$ value \\
\hline Age at diagnosis & $18.4 \pm 9.9$ & $14.3 \pm 8.8$ & $>0.1$ \\
Duration of diabetes (years) & $24.8 \pm 8.8$ & $28.4 \pm 9.3$ & $>0.1$ \\
Sex (M/F) & $89 / 61$ & $71 / 74$ & $>0.1$ \\
HbA1c $(\%)$ & $8.5 \pm 2$ & $8.2 \pm 2$ & $>0.1$ \\
Systolic BP (mmHg) & $161 \pm 17$ & $132 \pm 15$ & $<0.01$ \\
Diastolic BP (mmHg) & $91 \pm 10$ & $75 \pm 9$ & $<0.01$ \\
Serum creatinine (mmol/l) & $144 \pm 63$ & $95 \pm 22$ & $<0.01$ \\
\hline
\end{tabular}

$\mathrm{BP}$, blood pressure.

$P$ values were calculated using the Student's $t$-test. Significant values demonstrate clearly that the nephropathy group have renal impairment. 
the length of microsatellite repeats automatically using ABI Genescan and Genotyper software (Applied Biosystems).

\section{Statistical analysis}

The differences in clinical characteristics were analysed using the Student's $t$-test. Genotype frequencies were compared using the chi-squared test and Fisher's exact probability test. A probability of less than 1 in $20(P<0.05)$ was taken to be significant. Appropriate corrections were carried out for multiple comparisons $\left(P_{\mathrm{c}}\right)$ regarding the number of alleles analysed to ensure accurate significance values.

\section{Results}

The clinical characteristics of the type 1 diabetic cohorts are shown in Table 1. No significant differences were observed between the LDNN and DN groups in $\mathrm{HbA}_{1 \mathrm{c}}$, age and duration of diabetes. Significantly higher serum creatinine, and diastolic blood pressure were seen in the DN compared with the LDNN group $(P<0.01)$ indicative of their nephropathic status. The diabetic groups were well matched for gender and age. Controls were matched for age and sex as closely as possible. They were not diabetic or hypertensive (data not shown).

In total, eleven alleles were observed at the HSD11B2 $(\mathrm{CA})_{\mathrm{n}}$ microsatellite locus within intron I when groups 1,2 and 3 were analysed, these were termed alleles 138-158 (PCR product length) corresponding to 13-23 $(\mathrm{CA})_{\mathrm{n}}$ dinucleotide repeats respectively. The heterozygosity index for the $(\mathrm{CA})_{\mathrm{n}}$ repeat marker in this study was 0.60 .

The distribution of allele frequencies in all three groups is summarised in Table 2. Allele 152 was over represented in control subjects compared with LDNN subjects $\left(70.5 \%\right.$ vs $\left.57.6 \%, \chi^{2}=10.8, P_{c}<0.05\right)$ but no significant differences were observed between the DN and LDNN subjects for this allele. Allele 154 was significantly increased in the LDNN subjects when compared with the DN subjects ( $15.9 \%$ vs $7.0 \%, \chi^{2}=11.5$, $\left.P_{c}<0.01\right)$ but not when compared with the controls (15.9\% vs $\left.9.3 \% P_{c}<0.1\right)$ (Table 2 ).

Due to the established association between shorter alleles for this $(\mathrm{CA})_{\mathrm{n}}$ repeat and reduced $11 \beta-\mathrm{HSD} 2$ activity as previously reported by our group (17), the frequency of subjects carrying at least 1 allele $<152$ in length was compared between the three groups. A greater proportion of subjects carried at least 1 allele $<152$ in the diabetic nephropathy group compared with control subjects $\left(47.3 \%\right.$ vs $28.5 \%, \chi^{2}=11.37$, $\left.P_{\mathrm{c}}<0.01\right)$ but not in the LDNN group when compared with controls $\left(40.0 \%\right.$ vs $\left.28.5 \%, \chi^{2}=4.37, P_{c}<0.07\right)$. There was no difference seen between the DN and LDNN groups $\left(47.3 \%\right.$ vs $\left.40 \% P_{\mathrm{c}}<0.3\right)$ (Fig. 1$)$.

\section{Discussion}

Diabetic nephropathy affects up to $40 \%$ of all patients with type 1 diabetes and sibling and family studies suggest that genetic factors play a role (21-24). Systems that control sodium and extracellular volume homeostasis such as the renin-angiotensin system are relevant for genetic study in diabetic nephropathy because of an association with reduced plasma renin activity and hypertension. Therefore, there are sound reasons for evaluating $11 \beta-H S D 2$ in this regard. This enzyme plays a crucial role in regulating mineralocorticoid hormone action within the kidney by inactivating cortisol to cortisone, enabling aldosterone to occupy the mineralocorticoid receptor (5). Congenital deficiency due to mutation of the HSD11B2 gene

Table 2 Allele frequencies for the $(\mathrm{CA})_{\mathrm{n}}$ dinucleotide repeat marker in intron I of the HSD1 1B2 gene. $n$ refers to the number of alleles examined. Percentage values are shown in parentheses.

\begin{tabular}{lccc}
\hline Allele & $\begin{array}{c}\text { Control subjects } \\
(n=302)\end{array}$ & $\begin{array}{c}\text { DN subjects } \\
(n=300)\end{array}$ & $\begin{array}{c}\text { LDNN subjects } \\
(n=290)\end{array}$ \\
\hline 138 & $0(0)$ & $1(0.34)$ & $0(0)$ \\
140 & $3(0.99)$ & $9(3)$ & $5(1.72)$ \\
142 & $0(0)$ & $1(0.34)$ & $0(0)$ \\
144 & $0(0)$ & $3(1)$ & $1(0.34)$ \\
146 & $2(0.66)$ & $7(2.34)$ & $6(2.07)$ \\
148 & $16(5.3)$ & $15(5)$ & $13(4.49)$ \\
150 & $34(11.26)$ & $43(14.34)$ & $44(15.17)$ \\
152 & $213(70.53)^{\mathrm{a}}$ & $189(63)$ & $167(57.59)$ \\
154 & $28(9.27)$ & $21(7)$ & $46(15.86)^{\mathrm{b}}$ \\
156 & $6(1.99)$ & $10(3.34)$ & $8(2.76)$ \\
158 & $0(0)$ & $1(0.34)$ & $0(0)$ \\
\hline
\end{tabular}

$P$ values were calculated to test for real differences in allele frequencies by the chi-squared test. Significant differences were seen: ${ }^{\mathrm{a}} P_{\mathrm{c}}<0.05$ for allele 152 , LDNN vs controls; ${ }^{\mathrm{b}} P_{\mathrm{c}}<0.01$ for allele $154, \mathrm{LDNN}$ vs DN. 


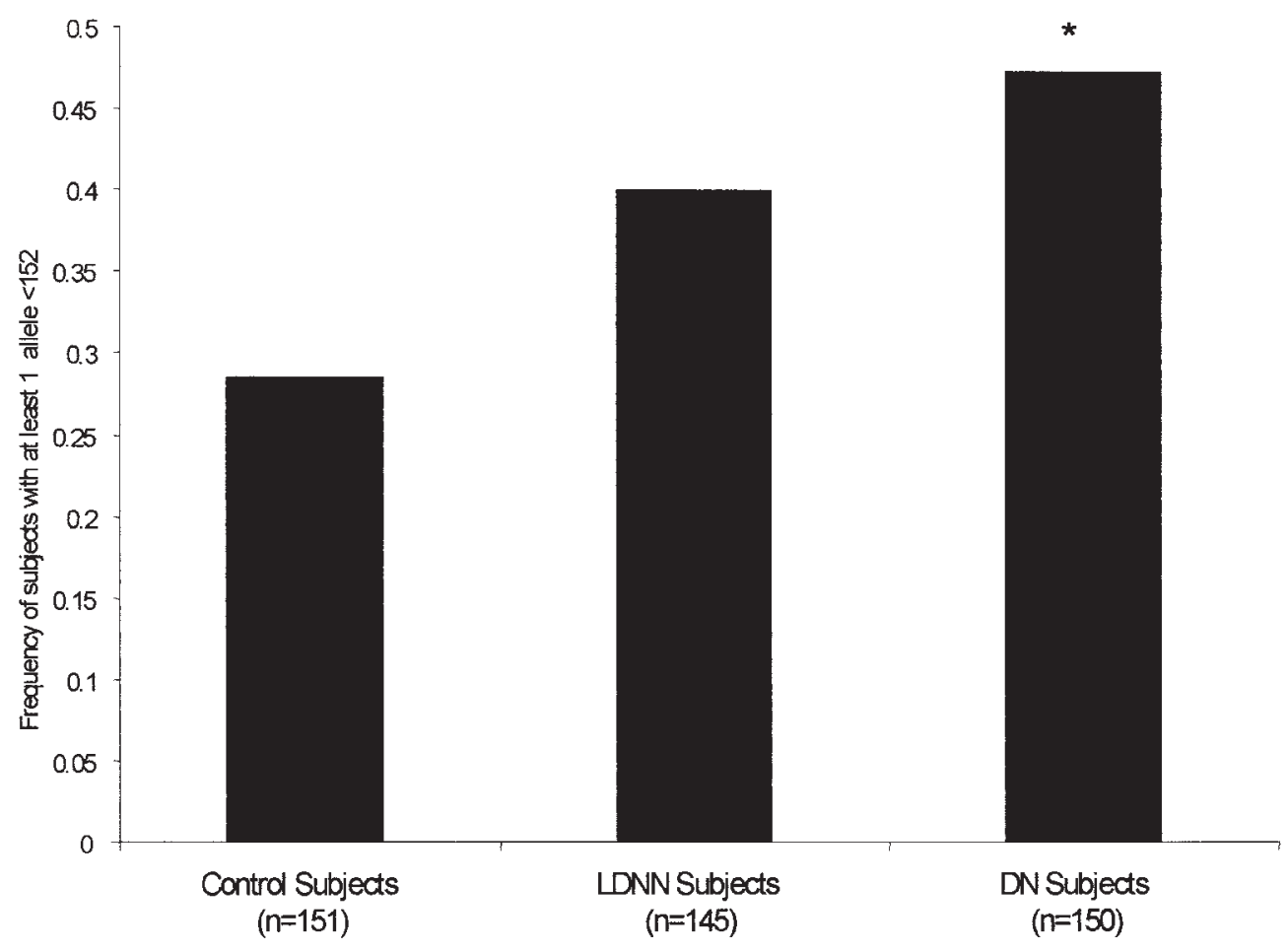

Figure 1 Frequency of subjects carrying at least 1 allele $<152 \mathrm{bp}$ in length. $P$ values were calculated to test for real differences in allele frequencies. There is an increase in the frequency of carriers in the DN group, ${ }^{*} P_{\mathrm{c}}<0.01$ vs controls.

results in mineralocorticoid hypertension (AME). Biochemical studies suggest impaired 11ß-HSD2 activity in patients with 'essential' hypertension (25), and although genetic linkage studies with the HSD11B2 gene have been negative (26), association of $11 \beta-H S D 2$ with intermediary hypertensive phenotypes has been reported. Watson et al. have demonstrated an association between the HSD11B2 gene and nephropathy in Blacks (27). Two separate studies have evaluated a microsatellite within intron I of the HSD11B2 gene, and have documented a genetic association with salt sensitivity in both normal subjects and patients with hypertension $(17,18)$. Short microsatellite alleles were over represented in saltsensitive compared with salt-resistant subjects. The same phenomenon was observed in Blacks compared with Caucasians (17), in keeping with predisposition to low-renin, salt-sensitive hypertension observed in Blacks (28). Furthermore, short alleles were associated with reduced 11ß-HSD2 activity, providing a genotype/phenotype relationship (17). A link between impaired $11 \beta-H S D 2$ activity and renal disease is also emerging. Patients with AME, together with mice lacking the HSD11B2 gene, have abnormal renal histology that cannot be explained solely by hypokalaemic nephropathy. Finally, 11ß-HSD2 activity is reduced in patients with nephrotic syndrome (6) partly explaining the intense sodium retention observed in this condition.

Type 1 diabetic patients show increased sensitivity to salt, more marked in patients with microalbuminuria
$(29,30)$ but the cause remains unclear. Our hypothesis was that reduced $11 \beta$-HSD2 activity may play a role in the pathogenesis of nephropathy in patients with type 1 diabetes or may contribute to the increased salt sensitivity that characterises diabetic nephropaths.

The variation in allele frequencies of a microsatellite marker in the first intron of the HSD11B2 gene indicated weak association with type 1 diabetes and diabetic nephropathy.

Differences in the distribution of the 152 allele were observed between LDNN and non-diabetic control subjects suggesting that the HSD11B2 locus may act as a susceptibility factor for diabetes. Both $11 \beta-H S D$ isozymes have been documented in the pancreas $(31,32)$, but to our knowledge $11 \beta-H S D 2$ is not expressed in pancreatic islet cells. Allele 154 was significantly over represented in the LDNN group when compared with the DN group but not when compared with the control group, suggesting that this genotype may protect against nephropathy in a diabetic group. This may be of borderline significance in that the DN group had no difference in allele 154 frequency compared with the control population.

Although there were minor differences between controls, DN and LDNN subjects in the distribution of the 152 and 154 alleles, further analysis demonstrated a significant increase in the number of the DN group carrying shorter alleles compared with non-diabetic controls $\left(P_{\mathrm{c}}=0.01\right)$. Although a similar trend was observed in the LDNN group, this was not significant 
$\left(P_{\mathrm{c}}=0.07\right)$. Thus the type 1 diabetic population demonstrates a HSD11B2 genotype similar to saltsensitive Caucasians and hypertensive Blacks (17). However, the lack of statistically significant differences between the DN and LDNN groups equally suggests that this may reflect the underlying diabetic state rather than nephropathy per se. Subjects within the LDNN group could, in time, progress to nephropathy and further genetic studies with greater power to detect association are required, if possible supported by biochemical data. Unfortunately, the subjects evaluated in this study were from a historical cohort and 24-hour urine collections were not available for analyses. However, Homma et al. demonstrated evidence for reduced $11 \beta-H S D 2$ activity in patients with diabetes mellitus and this was more marked in the subjects with renal failure (33). A reduction in renal $11 \beta$-HSD2 expression has also been documented in hypertensive, insulin-dependant diabetic rats (34), where corticosterone (the equivalent of cortisol in the rodent) may act to cause mineralocorticoid-mediated sodium retention and hypertension as a consequence (35). Finally, it is known that ACE inhibitors increase renal $11 \beta$-HSD 2 activity $(19,20)$ and it is exciting to speculate that the renal protective effect of ACE inhibitors in patients with type 1 diabetes may be mediated by this mechanism.

In conclusion, association between diabetic nephropathy and the HSD11B2 locus is marginal, with the observed variability between groups is suggestive of HSD11B2 being more of a factor in type 1 diabetes susceptibility. The HSD11B2 locus should not be dismissed as a candidate gene for nephropathy but its role appears to be less important in the light of these data. Our genotypic data suggest that patients with type 1 diabetes, independent of nephropathy, may be salt sensitive; this may have a detrimental role in terms of predisposing to hypertension, but equally may be an important constitutional factor favouring sodium retention and protecting against dehydration in a ketosis prone patient.

\section{Acknowledgements}

This work was supported by an MRC ROPA award (G9819149) and the British Diabetic Association. P M S is an MRC Senior Clinical Fellow.

\section{References}

1 Edwards CR, Stewart PM, Burt D, Brett L, McIntyre MA, Sutanto WS et al. Localisation of 11 beta-hydroxysteroid dehydrogenasetissue specific protector of the mineralocorticoid receptor. Lancet $19882986-989$.

2 Stewart PM, Corrie JE, Shackleton CH \& Edwards CR. Syndrome of apparent mineralocorticoid excess. A defect in the cortisol-cortisone shuttle. Journal of Clinical Investigation $198882340-349$.

3 Stewart P, Krozowski ZS, Gupta A, Milford DV, Howie AJ, Sheppard $\mathrm{MC}$ et al. Hypertension in the syndrome of apparent mineralocorticoid excess due to mutation of the 11 beta-hydroxysteroid dehydrogenase type 2 gene. Lancet 1996347 88-91.

4 White PC, Mune T \& Agarwal AK. 11Beta-hydroxysteroid dehydrogenase and the syndrome of apparent mineralocorticoid excess. Endocrine Reviews 199718 135-156.

5 Stewart PM \& Krozowski ZS. 11Beta-hydroxysteroid dehydrogenase. Vitamins and Hormones 199957 249-324.

6 Vogt B, Dick B, N'Gankam V, Frey FJ \& Frey BM. Reduced 11 beta-hydroxysteroid dehydrogenase activity in patients with the nephrotic syndrome. Journal of Clinical Endocrinology and Metabolism $1999 \mathbf{8 4} 811-814$.

7 Milford DV, Shackleton C \& Stewart PM. Mineralocorticoid hypertension and congenital deficiency of 11 beta-hydroxysteroid dehydrogenase in a family with the syndrome of 'apparent' mineralocorticoid excess. Clinical Endocrinology $1995 \quad 43$ $241-246$.

8 Kotelevtsev Y, Brown RW, Fleming S, Kenyon C, Edwards CR, Seckl JR et al. Hypertension in mice lacking 11beta-hydroxysteroid dehydrogenase type 2. Journal of Clinical Investigation $1999103683-689$.

9 Held PJ, Port FK, Webb RL, Wolfe RA, Garcia JR, Blagg CR et al. The United States Renal Data System's 1991 annual data report: an introduction. American Journal of Kidney Diseases $1991181-16$.

10 Chowdhury TA, Dyer PH, Kumar S, Barnett AH \& Bain SC. Genetic determinants of diabetic nephropathy. Clinical Science $199996221-230$.

11 Chowdhury TA, Dronsfield MJ, Kumar S, Gough SL, Gibson SP, Khatoon A et al. Examination of two genetic polymorphisms within the renin-angiotensin system: no evidence for an association with nephropathy in IDDM. Diabetologia $1996 \quad 39$ 1108-1114.

12 Chowdhury TA, Dyer PH, Kumar S, Gough SC, Gibson SP, Rowe BR et al. Lack of association of angiotensin II type 1 receptor gene polymorphism with diabetic nephropathy in insulindependent diabetes mellitus. Diabetic Medicine $1997 \quad 14$ $837-840$.

13 O'Hare JA, Ferriss JB, Brady D, Twomey B \& O'Sullivan DJ. Exchangeable sodium and renin in hypertensive diabetic patients with and without nephropathy. Hypertension 19857 II $43-\mathrm{II} 48$.

14 Weidmann P \& Ferrari P. Central role of sodium in hypertension in diabetic subjects. Diabetes Care 199114 220-232.

15 Cooper ME. Pathogenesis, prevention, and treatment of diabetic nephropathy. Lancet 1998352 213-219.

16 Strojek K, Grzeszczak W, Lacka B, Gorska J, Keller CK \& Ritz E. Increased prevalence of salt sensitivity of blood pressure in IDDM with and without microalbuminuria. Diabetologia 1995 38 1443-1448.

17 Agarwal AK, Giacchetti G, Lavery GG, Nikkila H, Palermo M, Ricketts $\mathrm{M}$ et al. CA-repeat polymorphism in intron 1 of HSD11B2: effects on gene expression and salt sensitivity. Hypertension 200036 187-194.

18 Lovati E, Ferrari P, Dick B, Jostarndt K, Frey BM, Frey FJ et al. Molecular basis of human salt sensitivity: the role of the 11beta-hydroxysteroid dehydrogenase type 2. Journal of Clinical Endocrinology and Metabolism 199984 3745-3749.

19 Ricketts ML \& Stewart PM. Regulation of 11 beta-hydroxysteroid dehydrogenase type 2 by diuretics and the renin-angiotensinaldosterone axis. Clinical Science 199996 669-675.

20 Riddle MC \& McDaniel PA. Renal 11beta-hydroxysteroid dehydrogenase activity is enhanced by ramipril and captopril. Journal of Clinical Endocrinology and Metabolism $1994 \quad \mathbf{7 8}$ $830-834$.

21 Andersen AR, Christiansen JS, Andersen JK, Kreiner S \& Deckert T. Diabetic nephropathy in Type 1 (insulin-dependent) diabetes: an epidemiological study. Diabetologia 198325 496-501. 
22 Borch-Johnsen K, Norgaard K, Hommel E, Mathiesen ER, Jensen JS, Deckert $\mathrm{T}$ et al. Is diabetic nephropathy an inherited complication? Kidney International 199241 719-722.

23 Fioretto P, Steffes MW, Barbosa J, Rich SS, Miller ME \& Mauer M. Is diabetic nephropathy inherited? Studies of glomerular structure in type 1 diabetic sibling pairs. Diabetes $1999 \mathbf{4 8}$ $865-869$.

24 Seaquist ER, Goetz FC, Rich S \& Barbosa J. Familial clustering of diabetic kidney disease. Evidence for genetic susceptibility to diabetic nephropathy. New England Journal of Medicine 1989 320 1161-1165.

25 Walker BR, Stewart PM, Shackleton CH, Padfield PL \& Edwards CR. Deficient inactivation of cortisol by 11 beta-hydroxysteroid dehydrogenase in essential hypertension. Clinical Endocrinology $199339221-227$.

26 Brand E, Kato N, Chatelain N, Krozowski ZS, Jeunemaitre X, Corvol P et al. Structural analysis and evaluation of the 11betahydroxysteroid dehydrogenase type 2 (11beta-HSD2) gene in human essential hypertension. Journal of Hypertension 199816 $1627-1633$

27 Watson B Jr, Bergman SM, Myracle A, Callen DF, Acton RT \& Warnock DG. Genetic association of 11beta-hydroxysteroid dehydrogenase type 2 (HSD11B2) flanking microsatellites with essential hypertension in blacks. Hypertension $1996 \mathbf{2 8}$ $478-482$

28 Weinberger MH. Salt sensitivity of blood pressure in humans. Hypertension 199627 481-490.

29 Gerdts E, Svarstad E, Myking OL, Lund-Johansen P \& Omvik P. Salt sensitivity in hypertensive type-1 diabetes mellitus. Blood Pressure $1996578-85$.
30 Nesovic M, Stojanovic M, Nesovic MM, Ciric J \& Zarkovic M. Microalbuminuria is associated with salt sensitivity in hypertensive patients. Journal of Human Hypertension $1996 \mathbf{1 0}$ $573-576$.

31 Albiston AL, Obeyesekere VR, Smith RE \& Krozowski ZS. Cloning and tissue distribution of the human 11beta-hydroxysteroid dehydrogenase type 2 enzyme. Molecular and Cellular Endocrinology 1994105 R $11-R 17$.

32 Davani B, Khan A, Hult M, Martensson E, Okert S \& Efendic S. Type 1 11beta-hydroxysteroid dehydrogenase mediates glucocorticoid activation and insulin release in pancreatic islets. Journal of Biological Chemistry 2000275 34841-34844.

33 Homma M, Tanaka A. Hino K, Takamura H, Hirano T, Oka K et al. Assessing systemic 11beta-hydroxysteroid dehydrogenase with serum cortisone/cortisol ratios in healthy subjects and patients with diabetes mellitus and chronic renal failure. Metabolism $200150801-804$.

34 Liu YJ. Nakagawa Y \& Ohzeki T. Gene expression of 11 betahydroxysteroid dehydrogenase type 1 and type 2 in the kidneys of insulin-dependent diabetic rats. Hypertension $1998 \quad \mathbf{3 1}$ $885-889$.

35 Liu YJ, Nakagawa Y, Toya K, Wang Y, Saegusa H, Nakanishi T et al. Effects of spironolactone on systolic blood pressure in experimental diabetic rats. Kidney International $2000 \quad \mathbf{5 7}$ 2064-2071.

Received 7 September 2001

Accepted 12 December 2001 